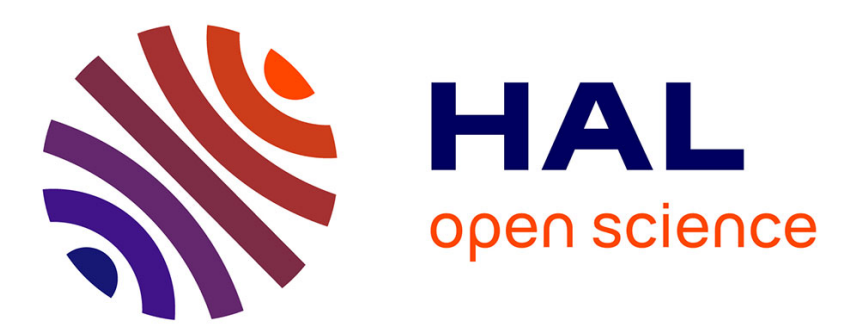

\title{
Incidence and risk factors for incisional hernia and recurrence: retrospective analysis of the French national database
}

B. Gignoux, Y. Bayon, Damien Martin, R. Phan, V. Augusto, B. Darnis, M. Sarazin

\section{To cite this version:}

B. Gignoux, Y. Bayon, Damien Martin, R. Phan, V. Augusto, et al.. Incidence and risk factors for incisional hernia and recurrence: retrospective analysis of the French national database. Colorectal Disease, 2021, 23 (6), pp.1515-1523. 10.1111/codi.15581 . hal-03140100

\section{HAL Id: hal-03140100 https://imt-mines-albi.hal.science/hal-03140100}

Submitted on 6 Sep 2021

HAL is a multi-disciplinary open access archive for the deposit and dissemination of scientific research documents, whether they are published or not. The documents may come from teaching and research institutions in France or abroad, or from public or private research centers.
L'archive ouverte pluridisciplinaire HAL, est destinée au dépôt et à la diffusion de documents scientifiques de niveau recherche, publiés ou non, émanant des établissements d'enseignement et de recherche français ou étrangers, des laboratoires publics ou privés. 
Incidence and risk factors for incisional hernia and recurrence: retrospective analysis of the French national database

B. Gignoux ${ }^{\mathrm{a}}$, Y. Bayon ${ }^{\mathrm{b}}$, D. Martinc, R. Phan ${ }^{\mathrm{d}}$, V. Augusto ${ }^{\mathrm{d}}$, B. Darnis ${ }^{\mathrm{a}}$, M. Sarazin ${ }^{\mathrm{d}}$

${ }^{\text {a }}$ Clinique de la Sauvegarde, Lyon, France

${ }^{\mathrm{b}}$ Sofradim Production, a Medtronic company, Trevoux ,France

${ }^{\mathrm{c}}$ Ecole des Mines d'Albi, Albi, France

${ }^{\mathrm{d}}$ Ecole des Mines de Saint-Etienne, Saint-Etienne, France

Corresponding author: B. Gignoux, Digestive Surgeon, Clinique de la Sauvegarde, Lyon, France. Tel: +33 (0)437 497010; Fax: +33 (0)437497013; Email: gignoux@chirurgien-digestif.com

\section{Acknowledgements}

Medical writing and editorial support was provided by Nicholas Paquette, $\mathrm{PhD}$ and Patrice Becker of Medtronic based on content and conclusions determined by the authors. 


\section{Abstract (247 Words) \\ Purpose}

To determine the rate of incisional hernia (IH) repair and risk factors for IH repair after laparotomy.

\section{Methods}

This population-based study used data extracted from the French (PMSI) database. All patients who had undergone a laparotomy in 2010, their hospital visits from 2010-2015, and patients who underwent a first IH repair in 2013 were included. Risk factors identified previously included: age, gender, high blood pressure (HBP), obesity, diabetes and chronic obstructive pulmonary disease (COPD).

\section{Results}

Among the 431619 patients who underwent a laparotomy in 2010, 5\% underwent IH repair between 2010 and 2015 . A high-risk list of the most frequent surgical procedures $(>100)$ with a significant risk of IH repair $(>10 \%$ at 5 years $)$ was established including 71863 patients (17\%, 65 procedures). Overall IH repair rate from the list was 17\%. Gastrointestinal (GI) surgery represented $89 \%$ of procedures with the majority of patients (72\%) undergoing lower GI tract surgery. IH repair rate was $56 \%$ at 1 year and $79 \%$ at 2 years. Risk factors for IH repair included obesity $(31 \%$ vs. 15\%, p<0.001), COPD (20\% vs. 15\%), HBP (19\% vs. 15\%) and diabetes (19\% vs. 16\%). Even for recurrence after IH repair, obesity was the main risk factor $(19 \%$ vs. $13 \%, \mathrm{p}<0.001)$

\section{Conclusion}

From the PMSI database, the real rate of IH repair after laparotomy was $5 \%$, increasing to $17 \%$ after digestive surgery. Obesity was the main risk factor with an IH repair rate of $31 \%$ after digestive surgery. Because of the important medicoeconomic consequences, prevention of IH after laparotomy in high-risk patients should be considered.

Key Words: Laparotomy; Incisional hernia; Hernia repair, Hernia recurrence; Healthcare costs; Quality of life 


\section{Introduction}

Incisional hernias (IHs) are a common complication of laparotomy involving the abdominal wall, with a risk of developing IH ranging from 5-20\% in published studies $(1,2)$ and a 5 -year prevalence of up to $69.1 \%$ in some high-risk patient groups (3). According to the systematic review and meta-regression conducted by Bosanquet et al. of 56 selected publications, comprising 14618 patients, the prevalence of IH after midline incision was 12.8\% (range: 0-35.6\%) at a weighted mean of 23.7 months (4). In a 10-year prospective study, Mudge and Hughes showed that $<50 \%$ of IHs occur in the first year after surgery (5), and in another study, Fink et al. showed that the IH rate increased significantly from $12.6 \%$ at 1 year to $22.4 \%$ at 3 years after surgery (6). The latter authors suggested that follow-up for at least 3 years should be mandatory to adequately assess the true incidence of IH after midline laparotomy.

Several risk factors have been associated with increased IH rate after midline laparotomy including higher patient age, type of surgery (surgery for abdominal aortic aneurysm or surgery using upper midline incision), previous laparotomy or previous IH (4), local wound infection (7-9), obesity $(4,9-12)$, the surgical technique used to close a midline abdominal incision $(9,13-15)$ and the presence of comorbidities including diabetes, tobacco smoke exposure (smokers and exsmokers), high blood pressure (HBP) and chronic obstructive pulmonary disease (COPD) (2).

Recurrence of IH is also a problem after incisional hernia repair (IH repair) with a prevalence of $27.7 \%$ at 2 years (16) and a cumulative 5 -year frequency of reoperation of $12.3 \%$, with over $23 \%$ of patients undergoing reoperation by 13 years (8). In the latter study, the 5 -year reoperation rate was $23.8 \%$ after the first IH repair, $35.3 \%$ after the second IH repair and $38.7 \%$ after the third IH repair (16). A large number of risk factors for IH recurrence have been identified including age $>45$ years, male gender, obesity, previous hernia repair, lateral hernia, concomitant digestive operations and surgical site complications, with patients having three or more risk factors most likely to suffer recurrence during followup (17). Mesh repair was an independent protective factor for IH recurrence $(1,16,17)$. Repeated IH repairs are generally more complicated and can lead to poor quality of life $(\mathrm{QoL})(18,19)$ and a vicious cycle of complications and costs $(20$, 21) as IH occurrence and recurrence after laparotomy involves significant direct and indirect medical costs. The median direct cost of IH repair was estimated to be 20000 US\$ by Alli et al. in 2018 (21) and Gillion et al. reported a mean total cost of IH repair in France in 2011 of $6451 €$, ranging from $4731 €$ for unemployed individuals to $10107 €$ for employed patients (22).

The French nationwide hospital discharge database, Programme de Médicalisation des Systèmes d'Informations (PMSI), has collected data from all public and private hospital stays in France, since 2006, including patient trajectories after laparotomy (23). It currently holds inpatient care data such as type of surgery, dates, diagnoses and hospital reimbursements for over 25 million hospital stays and 11 million patients, who can each be followed by a unique anonymous ID number. The database has been used increasingly to study trends in surgery in terms of practice and clinical outcomes.

Based on data extracted from the PMSI database, the present retrospective study aimed to assess the rate of IH repair after laparotomy in a large cohort of patients. In addition to defining the rate of IH repair, we hope to generate new 
information on the profiles of patients at risk, the impact of surgery type and comorbidities, the time to IH repair and recurrence rates.

\section{Material and methods}

\section{Data source}

Hospital and patient data were extracted from the French SNDS database (Système National des Données de Santé (National System of Health Data)), more specifically from its PMSI component.

\section{Study population}

For the first stage of the analysis, data were extracted for patients who were hospitalized for laparotomy in mainland France in 2010. For the second stage of the analysis, data were extracted for patients who were hospitalized for management of abdominal IH repair following surgery in mainland France in 2013.

\section{Selection criteria}

During their hospital stay in 2010, patients were selected who underwent surgical intervention including laparotomy according to Classification Commune des Actes Médicaux (CCAM) codes, representing a total of 549 codes, and surgical intervention for ventral hernia according to corresponding CCAM codes (i.e. LMMA004, LMMA010 and LMMC015) (24). Discriminatory elements that were considered included: patient age at the time of surgery, gender, and the presence of comorbidities identified during the hospital stay (coded according to the ICD-10 (International Classification of Diseases version 10) (25). Among the IH risk factors that were identified in the PMSI database, the following comorbidities were recorded: obesity (BMI $\geq 30)$ (E66_); diabetes (E10_, E11_, E12_, E13_, E14_); HBP (I1_) and COPD (J44_) (2), other surgical conditions can't be accessed through the PMSI database.

\section{Study organization}

The study was conducted between 2010 and 2015 inclusive, to allow enough time to track any possible ventral hernia complications after laparotomy. Linking hospital stays for each patient was done via the anonymized NIR (social security number) and the connection key between tables in the SNDS databases. The study consisted of two stages. Stage 1 consisted of the identification of patients who had undergone a laparotomy in 2010 and determination of their hospital visits over a 5-year period from 2010-2015. Patients were classified in two groups: (i) those with new PMSI records/events after ventral laparotomy; and (ii) patients without any new events. Patients were further filtered to isolate the initial laparotomy leading to most IH cases (i.e. the high-risk laparotomy list), according to two criteria: (i) $>100$ patients in 2010 per surgery; (ii) $>10 \%$ of IH repairs within the next 5 years after surgery. Stage 2 consisted of the identification of patients who had a first IH repair performed in 2013 from the high-risk laparotomy list. Any patient having another IH repair or primary ventral hernia repair between 2010 and 2013 was removed from the list. 
Comorbidities were identified from the PMSI data recorded in 2011, 2012 and 2013. For the corresponding patients, all recorded events were isolated to make up their hospital journey from 2010 to 2015 . The second stage of the study was intended to understand the rate of IH recurrence and the time from first IH repair to recurrence, and to evaluate these events based on initial laparotomy type and patient risk factors.

\section{Outcomes of interest}

The primary outcome for this study was the rate of IH repair after ventral laparotomy. The secondary outcomes were the time to IH repair after laparotomy, risk factors for IH repair including type of surgery and comorbidities and IH recurrence rates.

\section{Data treatment and statistical analysis}

Due to the high volume of data, use of the programming language Python was necessary to clean and convert the data. After treatment, Excel was used for data preparation and formatting. Statistical analysis was performed using Minitab $^{\text {TM }}$ v15.0 software and http://biostatgv.sentiweb.fr/?module=tests/chideux (Chi ${ }^{2}$ test). Qualitative variables are described by their relative number and frequency (\%), and quantitative variables are described as median values.

Bivariate statistical analyses were performed using two sample t-tests, Mann-Whitney or $\chi^{2}$ test to compare results using Minitab $^{\text {TM }}$ software and http://biostatgv.sentiweb.fr/?module=tests/chideux.

The rate of IH repair based on the first recorded occurrence after ventral laparotomy was calculated from Stage 1 study results and compared to the number obtained from Stage 2 study results. The total rate and cumulative rates over time are reported. Patients were categorized into four groups according to the type of comorbidity: (i) obesity; (ii) HBP;

(iii) COPD; and (iv) diabetes. A comparison of the IH repair rate between groups was carried out using the Mann Whitney test with a $5 \%$ risk level.

A process mining approach was used to model the journey of the patients after ventral laparotomy, in and out of hospital, including the journey preceding IH repair when recorded. This then supports simulation of a journey (e.g. MonteCarlo in the case of Markov models or discrete-event simulation in the case of flow models) (26).

\section{Results}

Analysis of laparotomies in mainland France in 2010

A total of 431719 patients who underwent ventral laparotomy in 2010 were retrieved from interrogation of the PMSI database and the 549 CCAM codes (ranging from C-section to colectomy) corresponding to laparotomies (Figure 1). The majority of the patients were female (71\%) and median age was 42 -years at the time of surgery. Among these 431 719 patients, 22088 (5\%) developed an IH and underwent their first IH repair surgery within 5 years (2010-2015) after laparotomy ( $55 \%$ female, median age at IH repair: 62 years vs. 40 -years [p $<0.001]$ for patients with no IH).

In order to determine the types of surgery most likely to lead to IH development, we excluded rare cases $(<100$ case number) and selected 65 CCAM codes that resulted in a relevant level of IH repair $(>10 \%)$ over 6 years. Using this 
selection criterion 71863 patients were identified as the high-risk laparotomy list. The flow diagram for the study population is presented in Figure 1.

The main comorbidities of the 71863 patients are shown in Figure 2. Mean rate of IH was 17\% overall and 13\% in patients without comorbidities. When assessing comorbidities individually, IH occurrence rates were $19 \%$ in patients with diabetes, $19 \%$ in patients with HBP and 20\% in those with COPD (Figure 2a). Strikingly, while non-obese patients had an IH occurrence rate of $15 \%$, obese patients had a significantly higher rate of $31 \%$ ( $<<0.001$, Chi ${ }^{2}$ test) (Figure $\mathbf{2 b}$ ), regardless of other comorbidities. The relative risk of IH repair for these comorbidities is shown in Table 1.

When the high-risk laparotomy list was examined, $89 \%$ of patients had undergone digestive surgery with the remaining $11 \%$ undergoing mainly gynecological or cardiovascular procedures (Figure 3a). The majority (72\%) of patients had surgical procedures involving the lower gastrointestinal tract (colon 29\%, rectum 22\%, small intestine 21\%) (Figure 3b). Time to first IH repair for the 71863 patients is shown in Figure 4. Over half (56\%) of IH repairs occurred during the first year after laparotomy and 79\% during the first 2 years. Median time to IH repair occurrence was 9.6 months.

\section{Clinical pathway of patients with IH repair after laparotomy}

A total of 21993 patients underwent IH repair in 2013. Of these patients, 18688 patients had an IH repair after previous laparotomy. A total of 7730 of these patients were selected who had not undergone a previous IH repair and were in the high-risk laparotomy list (Figure 1).

In this group the median time to IH repair was 7.7 months with an observed gender difference (6.2 months for females vs 8.6 months for males; $\mathrm{p}<0.001$ ). Median time to IH recurrence after repair was 14 months for females vs. 13 months for males. The overall recurrence rate was $14 \%$ (15\% females vs. $13 \%$ males).

When the impact of obesity was investigated there was no difference in time to first IH repair between non-obese and obese patients ( 8 months vs. 7 months, respectively), nor in the time to IH recurrence (13 months vs. 15 months, respectively). Among risk factors investigated in this study, obesity was the most significant. (19\% vs. 13\%, respectively; $\mathrm{p}<0.001)$. Notably, the occurrence rate of IH after digestive surgery increased from $17 \%$ in non-obese patients to $31 \%$ in obese subjects.

\section{Discussion}

This study, which used real-life data extracted from the PMSI database, analyzed the occurrence and recurrence of IH repairs after laparotomy surgery and according to the types of surgery. To our knowledge, this is the first study to investigate the incidence of IH repair after a laparotomy in France using the National database. Our study sheds light on the types of surgery most commonly associated with IH repairs. The PMSI database records repairs of incisional hernia, but not their incidence which is obviously higher. In 2007, from UK NHS figures, more than 120,000 laparotomies were performed and about 7,000 incisional hernia surgeries were subsequently reported. This corresponds to a $6 \%$ rate of incisional hernia surgery which appears to be about half the average evaluated incisional hernia incidence of about $13 \%$ 
(27). Bosanquet et al. (4) shared similar figures from a large metanalysis of selected 56 papers, corresponding to 14,618 patients. The observed incidence of incisional hernia was close to $13 \%$ at a weighted mean of 2 years. Half of the reported hernias were symptomatic and $36 \%$ were surgically repaired, representing a risk of IH repair of $5.2 \%$ after ventral laparotomies. Our study recorded IH repair within 3 years following surgery which corresponds to the timeframe when most occurrences appear (about 2/3 of cases) even if followed through 10 years (28).

In our total study population, the incidence of IH repair in the 5-years after laparotomy surgery was $5 \%$, which concurs with the reported incidence of $5-20 \%(1,2,4,27)$. As reported by Bosanquet et al. (4), we found that older age was associated with a greater risk of IH repair (median age at IH repair surgery: 63 years vs. 40 years for patients with no IH repair $[\mathrm{p}<0.001])$. We then analyzed the types of surgery most likely to lead to IH repair by excluding rare cases $(<100$ cases) and selecting $65 \mathrm{CCAM}$ codes (high-risk laparotomy list) that resulted in a relevant level of IH repair (>10\%) over 6 years. In this analysis, $89 \%$ of patients in this group had undergone digestive surgery with the remaining $11 \%$ undergoing mainly gynecological or cardiovascular procedures. The majority of patients (72\%) had surgery involving the lower gastrointestinal tract (colon 29\%, small intestine 21\%, rectum 22\%) (Figure 3b). In our study, the IH occurrence rates varied from one disease condition to another.

In a study published in 2013, Helgstrand et al. described the results of a prospective nationwide study on 3268 elective IH repairs registered in the Danish Ventral Hernia Database from 2007-2010 (29), with a median follow-up of 21 months. Readmission and reoperation rates 30-days post-IH repair surgery were $13.3 \%$ and $2.2 \%$, respectively. Independent risk factors for poor early outcomes included older age, open repair, large hernia and vertical incision at the primary laparotomy site. The cumulative risk of recurrence after IH repair ranged from 15.5-21.1\%. Risk factors for poor late outcomes included younger age, open repair, large hernia $(>7 \mathrm{~cm})$ and mesh positioning in open repair (29). Söderbäck et al. published the results of a population-based study on the incidence of IH and risk factors for developing IH following surgery for colorectal cancer using data registered in the Swedish Colorectal Cancer Register (30) and reported a cumulative incidence of $\mathrm{IH}$ of $5.3 \%, 5$ years after surgery. Risk factors for incisional hernia in this study included male gender, long operation time $>180$ min, obesity, age and post-operative wound complications (30).

Obesity (BMI $\geq 30$ ) is consistently reported as one of the main risk factors for IH and IH repair (8-10, 29). Our study confirms these findings as the RR of IH repair was highest for obese subjects ( $R R=2.06$ [95\%CI: 1.14-1.28]) and for obese subjects with other comorbidities (Table 1). While there was no difference in time after laparotomy surgery to first IH repair between obese and non-obese subjects (7 months vs. 8 months, respectively), the IH repair recurrence rate after first repair was significantly higher in obese subjects ( $19 \%$ vs. $15 \%$ for non-obese patients; $p<0.001, \chi^{2}$ test). Similar high Odds Ratios (OR) for IH recurrence in obese subjects have been described elsewhere (OR=4.4 [95\%CI: 1.2-15.5]; $\mathrm{p}=0.01$ ) (31).

The PMSI database records patient comorbidities and types of laparotomy surgeries but does not provide information on the surgery conditions (e.g. emergency vs elective surgery, wound closure technique, etc.) which can impact the clinical outcome. Emergency surgeries, for example, are well-known surgical conditions with more early complications that could compromise the quality of incisional hernia repair (32). 
Wound closure technique after laparotomy has also been shown to affect the rate of IH occurrence and mesh repair has been reported as an independent protective factor for IH recurrence $(1,16,17)$. In a systematic review of the literature on wound closure techniques including 23 randomized controlled trials (RCTs) (including nine using prophylactic mesh), Fortelny (1) reported that the use of slowly absorbable suture material for continuous closure using the small bites technique resulted in significantly less IHs compared to the large bites technique (OR=0.41 [95\%CI: 0.190.86]). These authors also showed that the use of prophylactic mesh versus suture midline closure resulted in a significant reduction in the $\mathrm{IH}$ rate $(\mathrm{OR}=0.14$ [95\% CI: $0.07-0.27])$. In a meta-analysis of $12 \mathrm{RCTs}$ involving 1661 patients conducted in 2017, Wang et al. also reported that mesh reinforcement can decrease the rate of IH compared with non-mesh ( $R R=0.19$ [95\% CI: 0.09-0.42]) and is associated with an improved QoL (33). These authors recommended the use of surgical mesh in some high-risk patients and suggested that individual risk factors should be taken into account when selecting patients who would most benefit from mesh insertion. Another recent meta-analysis and trial sequential analysis of 12 RCTs involving 1815 patients by Jairam et al. reported that prophylactic mesh reinforcement using an onlay or retromuscular technique after midline abdominal surgery significantly decreased the rate of IH occurrence in high-risk patients and that onlay mesh reinforcement could become the standard treatment for high-risk patients undergoing midline laparotomy (34).

Patient QoL has been reported to be severely affected by IH and IH repair $(18,19)$. When assessed using the Hernia-related Quality-of-life Assessment Tool (HerQLes) patients reported effects on QoL including chronic pain, interference with daily activities, and an impact on social and sexual activities (18). Using the 36-item Short Form Health Survey (SF-36), Saijo et al. compared pre- and 1-year post-operative QoL in 33 patients who underwent laparoscopic ventral and IH repair (19). Compared with pre-surgery SF-36 scores, scores for 5 of the 8 domains and 1 of the 3 SF-36 components improved 1-year post-surgery. QoL was correlated with obesity, hernia size, operating time and mesh size.

IH repair is a costly complication of surgery, but the actual healthcare costs associated with IH repair were largely unknown until recently. In 2016, Fisher et al. carried out a cost analysis of IH after elective abdominal surgery in 12373 patients, with a $3.5 \%$ incidence of surgically treated IH. They showed that the cost of surgical repair and associated management of complications was more than $\$ 175$ million (35). In another analysis of 14290 patients, Alli et al. reported a median direct cost of IH occurrence of 20000 US \$ (21). In 2016, Gillion et al. carried out a literature review and analyzed IH repair-associated direct costs (of healthcare), obtained from a cost analysis performed among 51 French public hospitals and involving $3239 \mathrm{IH}$ repairs, and indirect costs (costs of post-operative sick leave and loss of profits) estimated from the Hernia Club registry, involving 790 patients (22). The mean total cost for IH repair in France was estimated to be $6451 €$ in 2011, ranging from $4731 €$ for unemployed individuals to $10107 €$ for employed patients (22). Based on the IH repair occurrences of our study (22 $088 \mathrm{IH}$ repair after laparotomies done in 2010) the overall cost of primary IH repair in France should be about 140 million $€$, with 2011 cost figures. Gillion et al. estimated that reducing the incidence of $\mathrm{IH}$ after abdominal surgery by $5 \%$, by implementation of the European Hernia Society Guidelines on closure of abdominal wall incisions or by using prophylactic mesh in high-risk patients, could result in National cost savings of 4 million $€(22)$ and even more based on the IH repair observed in our study. 
This study has several strengths and limitations relating to the French PMSI database. The data used in the study were real-life data extracted from the PMSI database, thus the results are a true reflection of everyday events and their impact on healthcare, on a nationwide scale. The study design has the benefit over clinical trials in that the database provides massive amount of data for a very large patient cohort with long-term follow-up. Using the unique identification numbers, it is also possible to follow the same patient throughout their hospital journey without limitations of time from the recording of the first surgery event. A major limitation of the study is the high rate of IH repair at T0 (25\%), due to IH repair taking place during the same surgery or during another surgery in the same hospital stay.

Although we did not carry out a cost analysis of the IH repairs described in this study, the PMSI database contains sufficient data on the healthcare pathway of laparotomy patients at risk of IH to support a health economics study of IH repair in the future. In addition, the SNIIRAM database provides information on healthcare reimbursement and may give additional information on the costs incurred, in France.

\section{Conclusion}

From the National database, the real rate of IH repair after laparotomy was $5 \%$ and this increased to $17 \%$ after digestive surgery. Obesity was the main risk factor where the rate of IH repair increased to $31 \%$ after digestive surgery. Because of the important medico-economic consequences, surgeons should be aware of this problem and prevention of IH after laparotomy in high-risk patients should be considered.

\section{Declarations}

\section{Funding}

This study was sponsored and funded by Medtronic (Trevoux, France).

\section{Conflicts of Interest/Competing Interests}

This study was designed and sponsored by Medtronic (Trevoux, France). Medtronic did not influence the authors in the writing of this manuscript. 


\section{References}

1. Fortelny RH. Abdominal Wall Closure in Elective Midline Laparotomy: The Current Recommendations. Front Surg. 2018;5:34. Epub 2018/06/08. doi: 10.3389/fsurg.2018.00034. PubMed PMID: 29876355; PubMed Central PMCID: PMCPMC5974102.

2. Licari L, Salamone G, Campanella S, Carfi F, Fontana T, Falco N, et al. Use of the KSVM-based system for the definition, validation and identification of the incisional hernia recurrence risk factors. G Chir. 2019;40(1):32-8. Epub 2019/02/18. PubMed PMID: 30771796.

3. Alnassar S, Bawahab M, Abdoh A, Guzman R, Al Tuwaijiri T, Louridas G. Incisional hernia postrepair of abdominal aortic occlusive and aneurysmal disease: five-year incidence. Vascular. 2012;20(5):273-7. Epub 2012/09/18. doi: 10.1258/vasc.2011.oa0332. PubMed PMID: 22983541.

4. Bosanquet DC, Ansell J, Abdelrahman T, Cornish J, Harries R, Stimpson A, et al. Systematic Review and MetaRegression of Factors Affecting Midline Incisional Hernia Rates: Analysis of 14,618 Patients. PLoS One.

2015;10(9):e0138745. Epub 2015/09/22. doi: 10.1371/journal.pone.0138745. PubMed PMID: 26389785; PubMed Central PMCID: PMCPMC4577082.

5. Mudge M, Hughes LE. Incisional hernia: a 10 year prospective study of incidence and attitudes. Br J Surg. 1985;72(1):70-1. Epub 1985/01/01. doi: 10.1002/bjs.1800720127. PubMed PMID: 3155634.

6. Fink C, Baumann P, Wente MN, Knebel P, Bruckner T, Ulrich A, et al. Incisional hernia rate 3 years after midline laparotomy. Br J Surg. 2014;101(2):51-4. Epub 2013/11/28. doi: 10.1002/bjs.9364. PubMed PMID: 24281948.

7. Diener MK, Knebel P, Kieser M, Schuler P, Schiergens TS, Atanassov V, et al. Effectiveness of triclosan-coated PDS Plus versus uncoated PDS II sutures for prevention of surgical site infection after abdominal wall closure: the randomised controlled PROUD trial. Lancet. 2014;384(9938):142-52. Epub 2014/04/11. doi: 10.1016/S01406736(14)60238-5. PubMed PMID: 24718270.

8. Walming S, Angenete E, Block M, Bock D, Gessler B, Haglind E. Retrospective review of risk factors for surgical wound dehiscence and incisional hernia. BMC Surg. 2017;17(1):19. Epub 2017/02/23. doi: 10.1186/s12893-0170207-0. PubMed PMID: 28222776; PubMed Central PMCID: PMCPMC5320761.

9. Israelsson LA, Jonsson T. Overweight and healing of midline incisions: the importance of suture technique. Eur J Surg. 1997;163(3):175-80. Epub 1997/03/01. PubMed PMID: 9085058.

10. Henriksen NA, Helgstrand F, Vogt KC, Jorgensen LN, Bisgaard T, Danish Hernia D, et al. Risk factors for incisional hernia repair after aortic reconstructive surgery in a nationwide study. J Vasc Surg. 2013;57(6):1524-30, 30 e13. Epub 2013/04/04. doi: 10.1016/j.jvs.2012.11.119. PubMed PMID: 23548175.

11. Gruppo M, Mazzalai F, Lorenzetti R, Piatto G, Toniato A, Ballotta E. Midline abdominal wall incisional hernia after aortic reconstructive surgery: a prospective study. Surgery. 2012;151(6):882-8. Epub 2012/03/03. doi:

10.1016/j.surg.2011.12.032. PubMed PMID: 22381694. 
12. Chandeze MM, Moszkowicz D, Beauchet A, Vychnevskaia K, Peschaud F, Bouillot JL. Ventral hernia surgery in morbidly obese patients, immediate or after bariatric surgery preparation: Results of a case-matched study. Surg Obes Relat Dis. 2019;15(1):83-8. Epub 2018/11/24. doi: 10.1016/j.soard.2018.09.490. PubMed PMID: 30467034.

13. Varshney S, Manek P, Johnson CD. Six-fold suture:wound length ratio for abdominal closure. Ann R Coll Surg Engl. 1999;81(5):333-6. Epub 2000/01/25. PubMed PMID: 10645176; PubMed Central PMCID: PMCPMC2503300.

14. Israelsson LA, Jonsson T. Suture length to wound length ratio and healing of midline laparotomy incisions. Br J Surg. 1993;80(10):1284-6. Epub 1993/10/01. doi: 10.1002/bjs.1800801020. PubMed PMID: 8242299.

15. Romain B, Renard Y, Binquet C, Poghosyan T, Moszkowicz D, Gillion JF, et al. Recurrence after elective incisional hernia repair is more frequent than you think: An international prospective cohort from the French Society of Surgery. Surgery. 2020;168(1):125-34. Epub 2020/04/20. doi: 10.1016/j.surg.2020.02.016. PubMed PMID: 32305229. 16. Flum DR, Horvath K, Koepsell T. Have outcomes of incisional hernia repair improved with time? A populationbased analysis. Ann Surg. 2003;237(1):129-35. Epub 2002/12/24. doi: 10.1097/00000658-200301000-00018. PubMed PMID: 12496540; PubMed Central PMCID: PMCPMC1513979.

17. Dietz UA, Winkler MS, Hartel RW, Fleischhacker A, Wiegering A, Isbert C, et al. Importance of recurrence rating, morphology, hernial gap size, and risk factors in ventral and incisional hernia classification. Hernia. 2014;18(1):1930. Epub 2012/10/17. doi: 10.1007/s10029-012-0999-x. PubMed PMID: 23070583.

18. Lee TJ, Ulisney KL, Choudhuri AK, Swiger JL, Gibeily GJ. Understanding the patient perspective after ventral hernia repair. Hernia. 2019;23(5):995-1001. Epub 2019/08/07. doi: 10.1007/s10029-019-02015-6. PubMed PMID: 31385071.

19. Saijo F, Tokumura H, Narushima Y, Matsumura N, Sato K, Okazaki Y. The quality of life after laparoscopic ventral and incisional hernia repair with closure and non-closure of fascial defect. Surg Today. 2019;49(11):942-7. Epub 2019/06/17. doi: 10.1007/s00595-019-01834-5. PubMed PMID: 31203439.

20. Holihan JL, Alawadi Z, Martindale RG, Roth JS, Wray CJ, Ko TC, et al. Adverse Events after Ventral Hernia Repair: The Vicious Cycle of Complications. J Am Coll Surg. 2015;221(2):478-85. Epub 2015/07/25. doi: 10.1016/j.jamcollsurg.2015.04.026. PubMed PMID: 26206646.

21. Alli VV, Zhang J, Telem DA. Impact of incisional hernia development following abdominal operations on total healthcare cost. Surg Endosc. 2018;32(5):2381-6. Epub 2017/12/14. doi: 10.1007/s00464-017-5936-8. PubMed PMID: 29234938.

22. Gillion JF, Sanders D, Miserez M, Muysoms F. The economic burden of incisional ventral hernia repair: a multicentric cost analysis. Hernia. 2016;20(6):819-30. Epub 2016/03/05. doi: 10.1007/s10029-016-1480-z. PubMed PMID: 26932743.

23. Tuppin P, Rudant J, Constantinou P, Gastaldi-Menager C, Rachas A, de Roquefeuil L, et al. Value of a national administrative database to guide public decisions: From the systeme national d'information interregimes de l'Assurance Maladie (SNIIRAM) to the systeme national des donnees de sante (SNDS) in France. Rev Epidemiol Sante Publique. 2017;65 Suppl 4:S149-S67. Epub 2017/08/02. doi: 10.1016/j.respe.2017.05.004. PubMed PMID: 28756037. 
24. Trombert-Paviot B, Rector A, Baud R, Zanstra P, Martin C, van der Haring E, et al. The development of CCAM: the new French coding system of clinical procedures. Health Inf Manag. 2003;31(1):1-11. Epub 2003/01/01. doi: 10.1177/183335830303100103. PubMed PMID: 19468141.

25. ICD-10 Version: 2019. International Statistical Classification of Diseases and Related Health Problems 10th Revision. Available from: https://icd.who.int/browse10/2019/en.

26. Phan R SM, Augusto V, Martin A (eds) (2019). Clinical pathway analysis using process mining and discreteevent simulation. Proceedings of the 2019 Winter Simulation Conference: IEEE Press; [cited 2019]. Available from: https://www.informs-sim.org/wsc19papers/441.pdf.

27. Al Chalabi H, Larkin J, Mehigan B, McCormick P. A systematic review of laparoscopic versus open abdominal incisional hernia repair, with meta-analysis of randomized controlled trials. Int J Surg. 2015;20:65-74. Epub 2015/06/16. doi: 10.1016/j.ijsu.2015.05.050. PubMed PMID: 26074289.

28. Kockerling F, Koch A, Lorenz R, Schug-Pass C, Stechemesser B, Reinpold W. How Long Do We Need to Follow-Up Our Hernia Patients to Find the Real Recurrence Rate? Front Surg. 2015;2:24. Epub 2015/07/03. doi: 10.3389/fsurg.2015.00024. PubMed PMID: 26137464; PubMed Central PMCID: PMCPMC4468742.

29. Helgstrand F, Rosenberg J, Kehlet H, Jorgensen LN, Bisgaard T. Nationwide prospective study of outcomes after elective incisional hernia repair. J Am Coll Surg. 2013;216(2):217-28. Epub 2012/12/12. doi:

10.1016/j.jamcollsurg.2012.10.013. PubMed PMID: 23219350.

30. Soderback H, Gunnarsson U, Hellman P, Sandblom G. Incisional hernia after surgery for colorectal cancer: a population-based register study. Int J Colorectal Dis. 2018;33(10):1411-7. Epub 2018/07/19. doi: 10.1007/s00384-0183124-5. PubMed PMID: 30019246; PubMed Central PMCID: PMCPMC6133070.

31. Juvany M, Hoyuela C, Carvajal F, Trias M, Martrat A, Ardid J. Long-term follow-up (at 5 years) of midline incisional hernia repairs using a primary closure and prosthetic onlay technique: recurrence and quality of life. Hernia. 2018;22(2):319-24. Epub 2018/01/20. doi: 10.1007/s10029-018-1730-3. PubMed PMID: 29349615.

32. Zafar H, Zaidi M, Qadir I, Memon AA. Emergency incisional hernia repair: a difficult problem waiting for a solution. Ann Surg Innov Res. 2012;6(1):1. Epub 2012/01/06. doi: 10.1186/1750-1164-6-1. PubMed PMID: 22216761; PubMed Central PMCID: PMCPMC3261089.

33. Wang XC, Zhang D, Yang ZX, Gan JX, Yin LN. Mesh reinforcement for the prevention of incisional hernia formation: a systematic review and meta-analysis of randomized controlled trials. J Surg Res. 2017;209:17-29. Epub 2016/12/30. doi: 10.1016/j.jss.2016.09.055. PubMed PMID: 28032555.

34. Jairam AP, Lopez-Cano M, Garcia-Alamino JM, Pereira JA, Timmermans L, Jeekel J, et al. Prevention of incisional hernia after midline laparotomy with prophylactic mesh reinforcement: a meta-analysis and trial sequential analysis. BJS Open. 2020;4(3):357-68. Epub 2020/02/15. doi: 10.1002/bjs5.50261. PubMed PMID: 32057193; PubMed Central PMCID: PMCPMC7260413.

35. Fischer JP, Basta MN, Mirzabeigi MN, Bauder AR, Fox JP, Drebin JA, et al. A Risk Model and Cost Analysis of Incisional Hernia After Elective, Abdominal Surgery Based Upon 12,373 Cases: The Case for Targeted Prophylactic 
Intervention. Ann Surg. 2016;263(5):1010-7. Epub 2015/10/16. doi: 10.1097/SLA.0000000000001394. PubMed PMID: 26465784; PubMed Central PMCID: PMCPMC4825112. 
Table 1. Comorbidities and relative risk of incision hernia after laparotomy

\begin{tabular}{llll}
\hline & Relative risk & {$[\mathbf{9 5 \%} \mathbf{C I}]$} & $\mathbf{p}$ \\
\hline Diabetes & 1.17 & {$[1.12-1.22]$} & $<0.0001$ \\
HBP & 1.27 & {$[1.23-1.31]$} & $<0.0001$ \\
COPD & 1.21 & {$[1.14-1.28]$} & $<0.0001$ \\
Obesity & 2.06 & {$[1.99-2.14]$} & $<0.0001$ \\
Obesity + diabetes & 1.73 & {$[1.63-1.84]$} & $<0.0001$ \\
Obesity + HBP & 1.91 & {$[1.85-2.01]$} & $<0.0001$ \\
Obesity + COPD & 1.76 & {$[1.59-1.94]$} & $<0.0001$ \\
\hline
\end{tabular}


Figure 1. Flow diagram of the study populations analyzed.

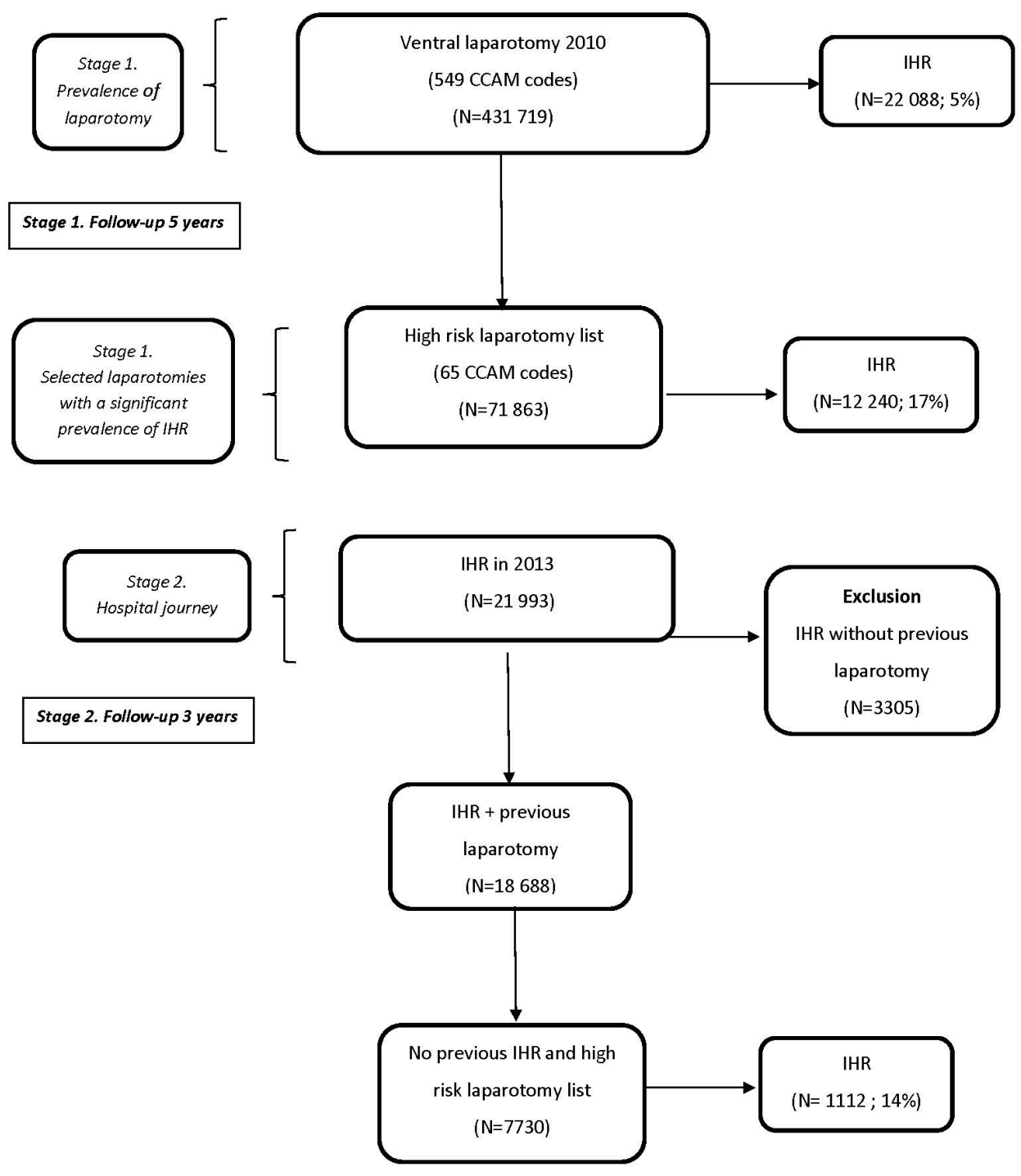

codi_15581_f1.jpg 
Figure 2. Rates of IH repair in the patient population, extracted from the high-risk laparotomy list ( $N=71$ 863)

Figure 2a. Rate of $\mathrm{IH}$ repair according to comorbidities

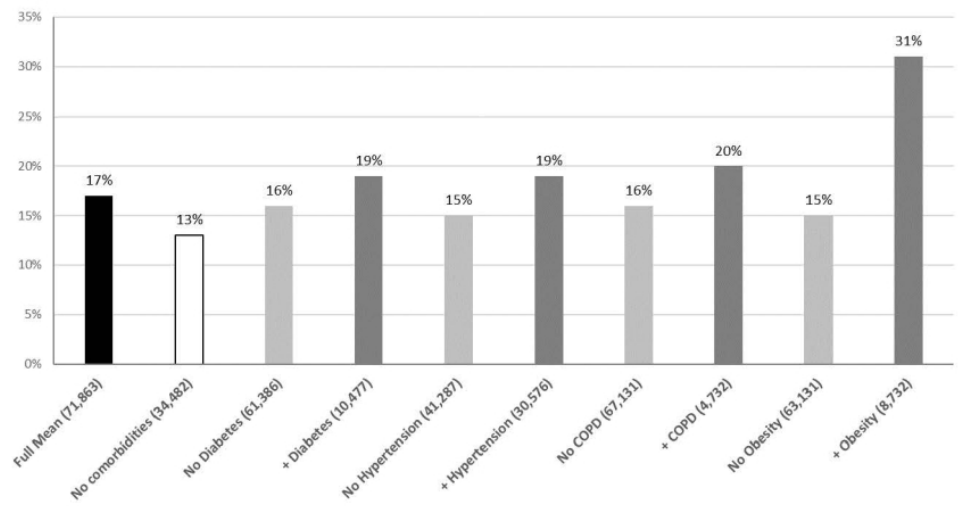

Figure $2 \mathrm{~b}$. Rate of $\mathrm{IH}$ repair in obese patients without or with additional comorbidities

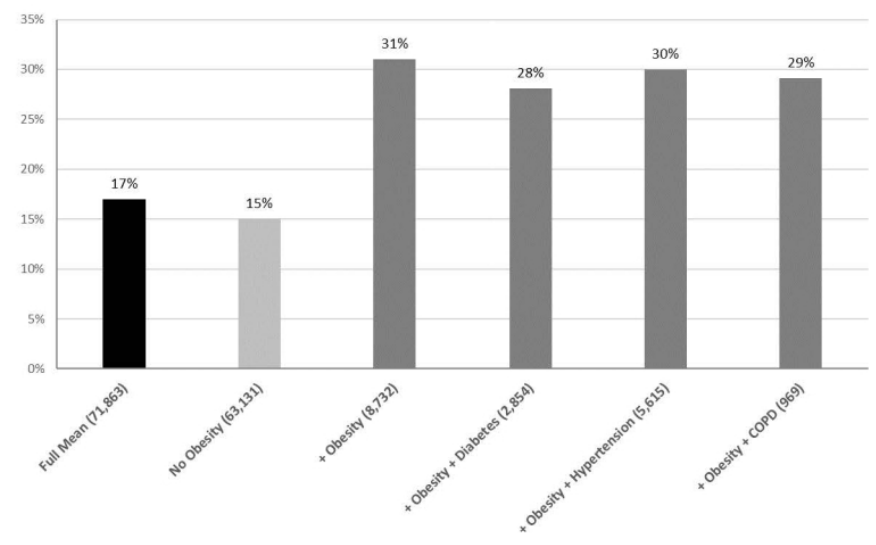

codi_15581_f2.jpg 
Figure 3a. Proportion ( $\mathrm{n}, \%)$ of patients by type of laparotomy surgery in the high-risk laparotomy list (N=71 863).

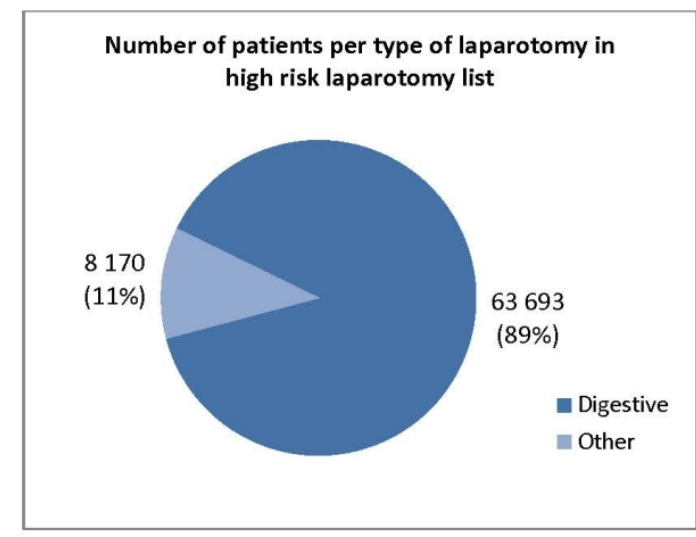

Figure 3b. Proportion (n, \%) of patients undergoing digestive surgery in the high-risk laparotomy list.

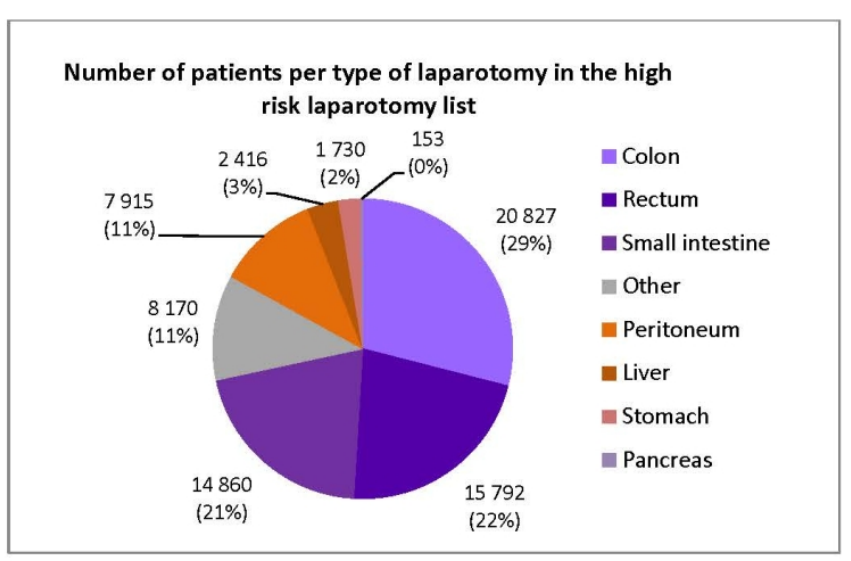

codi_15581_f3.jpg 
Figure 4. Time to occurrence of $\mathrm{IH}$ repair for the high-risk laparotomy list ( $\mathrm{N}=71 \mathrm{863})$.

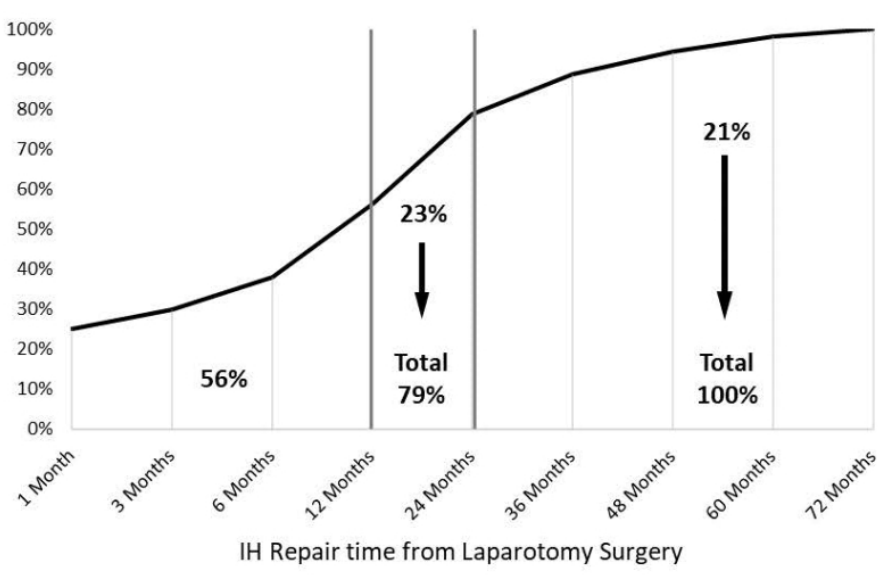

codi_15581_f4.jpg 